REVIEW

MECHANISMS IN ENDOCRINOLOGY

\title{
Endogenous sex steroids and cardio- and cerebro-vascular disease in the postmenopausal period
}

Theodora Pappa and Maria Alevizaki

Endocrine Unit, Department of Medical Therapeutics, Athens University School of Medicine, ALEXANDRA Hospital, 80 Vassilissis Sofias Avenue, 11528 Athens, Greece

(Correspondence should be addressed to T Pappa; Email: dorispappas@hotmail.com)

\begin{abstract}
Objective: Cardio- and cerebro-vascular diseases are two leading causes of death and long-term disability in postmenopausal women. The acute fall of estrogen in menopause is associated with increased cardiovascular risk. The relative contribution of androgen to this risk is also being recognized. The use of more sensitive assays for estradiol measurement and the study of receptor and carrier protein gene polymorphisms have provided some new information on the clinical relevance of endogenous sex steroids. We provide an update on the role of endogenous sex steroids on cardio- and cerebro-vascular disease in the postmenopausal period.

Design and methods: We performed a PubMed search using the terms 'endogenous estrogen', 'androgen', 'cardiovascular disease', 'cerebro-vascular disease', 'stroke', 'carotid artery disease', and 'subclinical atherosclerosis'.

Results: The majority of studies show a beneficial effect of endogenous estrogen on the vasculature; however, there are a few studies reporting the contrary. A significant body of literature has reported associations of endogenous estrogen and androgen with early markers of atherosclerosis and metabolic parameters. Data on the relevance of endogenous sex steroids in heart disease and stroke are inconclusive.

Conclusions: Most studies support a beneficial role of endogenous estrogens and, probably, an adverse effect of androgens in the vasculature in postmenopausal women. However, the described associations may not always be considered as causal. It is possible that circulating estrogen might represent a marker of general health status or alternatively reflect the sum of endogenous androgens aromatized in the periphery. Elucidating the role of sex steroids in cardio- and cerebro-vascular disease remains an interesting field of future research.
\end{abstract}

European Journal of Endocrinology 167 145-156

\section{Introduction}

Coronary heart disease (CHD) and stroke represent two leading causes of death and long-term disability in Western societies. Premenopausal women enjoy an innate protection that is lost at the menopausal transition, when their cardio- and cerebro-vascular risk increases to reach that of the male population. This has long been considered to be due to the abrupt fall of endogenous estrogen production. However, studies from the Women's Health Initiative (WHI) evaluating the role of hormone replacement therapy (HRT) could not provide consistent evidence of a beneficial effect of HRT on primary and secondary cardio- and cerebro-vascular protection $(1,2)$. The timing of HRT initiation has been hypothesized as a factor modulating estrogens' actions on the vasculature. Given the increased life span, women are becoming a growing body of the population to spend a significant period at an age associated with increased cardio- and cerebro-vascular risk.

Older studies focusing on the role of endogenous estrogens in the postmenopausal period did not show a significant association between circulating estrogen and cardiovascular disease (CVD) or CVD risk factors $(3,4,5)$. After the publication of the WHI studies and the negative findings of HRT on cardio- and cerebro-vascular risk, the importance of endogenous sex hormones in cardio- and cerebro-vascular disease was rather neglected. Lately, the development of ultrasensitive assays has allowed the measurement of endogenous estradiol with appreciable precision even at the very low levels seen in the postmenopausal period. This advent of the laboratory techniques has renewed the interest to expand our current knowledge and investigate the relevance of endogenous sex hormones in cardio- and cerebro-vascular disease. 
In this paper, we attempt to provide a succinct clinical update of the current literature regarding the role of endogenous estrogen and androgen in women in the peri- and postmenopausal period. We performed a search in the PubMed database since 1990 using the terms 'estrogen', 'endogenous estrogen', 'androgen', 'CVD', 'cerebro-vascular disease', 'subclinical atherosclerosis', 'carotid artery disease', and 'stroke'. We included studies published in English assessing women in the peri- and postmenopausal period. Evaluating the effect of exogenous estrogens was beyond the scope of this review and, therefore, evidence from HRT studies is not included.

\section{Risk of cardio- and cerebro-vascular disease}

Several studies have evaluated the relationship of endogenous sex steroids with CVD, whereas fewer data are available for cerebro-vascular disease. Women experiencing an acute stroke are older compared with men. Stroke severity and mortality rates are higher in elderly women compared with men, possibly due to the increased prevalence of cardioembolic stroke associated with more severe neurological damage and degree of handicap $(6,7)$. In the prospective population-based study of Barrett-Connor \& Goodman-Gruen (3) on 651 postmenopausal women, endogenous estrogen levels were not associated with the risk of developing CVD. Cauley et al. (8) studied 87 postmenopausal women undergoing diagnostic coronary angiography and found no significant difference in estrone levels between women with and without coronary artery disease (CAD). Similar results were reported by the Swedish study of Nilsson et al. (9) who evaluated 195 women aged 71-80 years followed for 8 years; no difference in estradiol levels was found with respect to the development of CVD.

Concerning cerebro-vascular disease, endogenous estradiol was recently identified as an indicator of stroke risk, especially in women with central adiposity (10). In a smaller case-control study on women with peripheral arterial disease, Price et al. (4) found no significant difference in estrogen levels between patients and the age-matched control group.

In the study of Chen et al., 99 women with CVD were matched 1:2 for age with a control group. Although in the initial model estradiol levels were associated with higher risk for CVD, this relationship did not remain significant after adjusting for hypertension, body mass index (BMI), and lipid concentration (11). Likewise, Rexrode et al. (12) found similar estradiol levels in nonHRT users with CVD and the age-matched controls.

Concerning endogenous androgens, Barrett-Connor \& Goodman-Gruen (3) did not find a significant association with the risk of developing CVD and the same was shown in another study on peripheral arterial disease (4). In the above-mentioned study of Rexrode et al., CVD patients had higher free androgen index (FAI) compared with the control group. However, after adjusting for BMI, hypertension, and other CVD risk factors, this association lost its statistical significance (12). A positive association between endogenous androgen and CVD risk was reported in two recent studies. In the cross-sectional study of Patel et al. evaluating 344 women aged 65-98 years, total testosterone was associated with a threefold greater risk of CHD. In addition, a significant association was found between total and free testosterone and an adverse metabolic profile, i.e. insulin resistance and abdominal obesity (13). In accordance were the findings of Page-Wilson et al., who studied 200 nondiabetic postmenopausal women, 98 of them with CVD and 102 serving as matched controls. The FAI was significantly higher in women with CVD compared with controls and was also associated with $\mathrm{HbAlc}$ in the multivariate analysis (14).

The polycystic ovary syndrome (PCOS) is the most frequent endocrinopathy associated with hyperandrogenemia and CVD risk factors in women of reproductive age (15). Markopoulos et al. (16) and Puurunen et al. (17) recently reported that increased androgen production and a proinflammatory profile persist in PCOS women in their menopausal transition. In a meta-analysis by de Groot et al. (18), PCOS women were recognized to harbor a twofold increased risk for arterial disease (CHD and stroke) compared with nonPCOS subjects, independent of their BMI. Furthermore, Shaw et al. studied 390 postmenopausal women followed for 5 years; 104 of them presented clinical features of PCOS, i.e. irregular menstrual cycles premenopausally and current biochemical hyperandrogenemia. It was shown that $79 \%$ of women with features of PCOS experienced a 5-year CVD event-free survival compared with $89 \%$ of non-PCOS women, and this finding was independent of hypertension and diabetes status, as well as other CVD risk factors (19). However, there are also studies reporting similar CVD morbidity and mortality rates in PCOS subjects and control populations (20).

In contrast to studies linking androgens to an adverse CVD profile, there are data supporting an inverse relationship of endogenous androgen with carotid artery disease. In the case-control study of Debing et al. in 56 patients undergoing carotid artery endarterectomy and 56 age-matched controls, it was found that total testosterone and $\Delta 4$-androstenedione levels were lower in the patients' group compared with the controls. The inverse association of circulating androgens with carotid atherosclerosis remained significant even after controlling for classical CVD risk factors (21). These results were reproduced in the same year by Montalcini et al. (22). Furthermore, Golden et al. (23) also showed a negative association 
of total testosterone levels with the risk for carotid atherosclerosis.

It appears that the association of circulating sex steroid levels with CVD in the postmenopausal period is complex, and it is difficult to draw definite conclusions or prove an etiological relationship. In their populationbased study on septuagenarian women with CVD, Naessen et al. (24) suggested that the increased aromatase index (estradiol to testosterone ratio) in the study population might represent a physiological response counteracting the vascular alterations in the atherosclerotic process. Furthermore, in a prospective, 12-year follow-up study on 639 postmenopausal women, Laughlin et al. (25) showed a U-shaped association of bioavailable testosterone with the development of CHD, where women at both low and high levels of testosterone were at a significantly increased risk of $\mathrm{CHD}$. It might be the case that endogenous androgens, at a certain range, have a beneficial action on the female cardiovascular system. In another study, Braunstein et al. found that androgen and estrogen levels correlated closely in women with suspected CAD, even after adjusting for BMI and insulin resistance. This highlights the need to take into consideration and control for the independent effect of each sex steroid hormone (26).

In summary, the majority of reports in the current literature - briefly presented in Table 1 - do not support a significant link between endogenous sex steroids and the risk of CVD. It is clear that the androgenicity characterizing PCOS women even in the postmenopausal period appears to be an independent CVD risk factor; however, this is a more complex disease. It is possible that variation of hormonal levels from a certain range, either up- or downwards, is related to the development of atherosclerotic changes.

\section{Severity and mortality of cardio- and cerebro-vascular disease}

There are only a few studies evaluating the role of endogenous sex steroids on the severity and mortality in CVD and even fewer in cerebro-vascular disease. One of the first reports comes from Phillips et al., who studied 60 postmenopausal women undergoing coronary angiography. The authors found a significant positive association of free testosterone levels with the degree of CAD (27). Our group has recently shown a positive association of $\Delta 4$-androstenedione with stroke severity on admission in a population of 302 acute stroke women (28). In this study, $\Delta 4$-androstenedione was also an independent predictor of short-term mortality, even after adjusting for traditional risk factors for stroke.

Furthermore, we showed an independent positive association of circulating estradiol with stroke severity, short-term mortality, and handicap in the same stroke patients' cohort (29). Except for the circulating levels, sensitivity to sex hormone actions as indicated from receptor gene polymorphism studies may also have some importance. For example, we recently reported a significant relationship of the androgen receptor and the estrogen receptor $\alpha$ gene polymorphism with the severity of CAD in postmenopausal women undergoing coronary angiography $(30,31)$.

With respect to CVD mortality, evidence in the current literature is rather contradictory and inconclusive. The prospective studies of Barrett-Connor \& Goodman-Gruen (3) and Nilsson et al. (9) did not show an association of endogenous estrogen and androgen levels with CVD mortality. In the recent large study of Sievers et al. (32) assessing 2914 women followed for 4.5 years, it was demonstrated that women with the

Table 1 Cumulative results of studies investigating associations of endogenous estrogen and androgen levels with cardio- and cerebrovascular disease risk in postmenopausal women (reference in parenthesis).

\begin{tabular}{llcl}
\hline Reference & Study type & $\begin{array}{c}\text { Number of } \\
\text { participants }\end{array}$ & Result \\
\hline$(3)$ & 19-year FU, population-based & 651 & No association of E and A with CVD risk \\
$(8)$ & Case-control & 87 & No association of E with CHD risk \\
$(9)$ & 8-year FU, population-based & 195 & No association of E with CVD risk \\
$(10)$ & Prospective case-control & 415 & Positive association of E with increased stroke risk \\
$(4)$ & Case-control & 90 & No association of E and A with peripheral arterial disease \\
$(11)$ & Prospective case-control & 297 & No independent association of E with CVD risk \\
$(12)$ & Case-control & 400 & No independent association of E and A with CVD risk \\
$(13)$ & Cross-sectional & 344 & Positive association of total testosterone with threefold \\
$(14)$ & Case-control & 200 & higher CHD risk \\
$(21)$ & Case-control & 112 & Positive association of A with CVD \\
$(22)$ & Cross-sectional & 101 & Inverse association of A with carotid atherosclerosis \\
$(23)$ & Case-control & 364 & Inverse association of A with carotid atherosclerosis \\
$(25)$ & Inverse association of total testosterone with carotid & atherosclerosis \\
& 12-year FU, population-based & 639 & U-shaped association of A with CHD risk
\end{tabular}

FU, follow-up; E, estrogen; A, androgen; CVD, cardiovascular disease; CHD, coronary heart disease. 
lowest testosterone levels are at increased risk of allcause mortality and CVD, an association that was independent of traditional risk factors. An interesting finding comes from the population-based, 9-year followup study of Maggio et al. (33) on 509 women older than 65 years. In this study, higher estradiol levels were an independent determinant of all-cause mortality after adjusting for age, insulin resistance, inflammatory factors, and comorbidities, in line with our recent findings (29). The authors support the hypothesis that circulating estrogen might be part of an adaptive process or represent a marker of general health and metabolic status (33). A synopsis of the current literature on the associations of sex steroids with the severity and mortality of cardio- and cerebro-vascular disease is presented in Table 2.

The bioavailability of circulating sex steroids is regulated by the sex hormone-binding globulin (SHBG) concentration. Several studies have evaluated possible associations between CVD and circulating SHBG levels $(12,14,23,27)$. The majority of them has shown an inverse relationship, although this was significantly attenuated following adjustment for BMI and other CVD risk factors. Currently, there is increased interest in clarifying whether SHBG has a direct, independent association with CVD, as it is also strongly associated with insulin resistance. Studies on SHBG gene polymorphisms have shown an association of the SHBG gene promoter polymorphism with the severity of CAD, as well as early markers of atherosclerosis in postmenopausal women $(34,35)$. However, discussing studies on the clinical relevance of $S H B G$ in cardio- and cerebro-vascular disease is not part of this review and the reader is referred to recent reviews $(36,37)$.

One could conclude that endogenous sex steroids might serve as surrogate markers of the severity of underlying disease and as a useful adjunct to identify earlier subjects at increased risk of an adverse CVD outcome. The observed associations of sex steroid levels with disease severity and mortality do not necessarily suggest a causative relationship but may represent the effect of the disease on the metabolic status.

\section{Early markers of atherosclerosis}

The ultrasonographic evaluations of carotid intimamedia thickness (IMT), carotid-femoral pulse wave velocity (PWV), and flow-mediated dilation of branchial artery (FMD) are technically easy, cheap, and most importantly noninvasive and radiation-free methods to estimate arterial atherosclerosis, arterial stiffness, and early endothelial changes in otherwise healthy individuals. In the last decades, these methods have been widely studied as markers of early atherosclerosis.

In the study of Creatsa et al. (38) on 120 healthy postmenopausal women, estradiol levels were not related to the aforementioned vascular parameters, whereas Ouyang et al. (39) did not find a significant correlation of estradiol levels with common carotid IMT or coronary calcification. Similarly, in a subgroup of the Multi-Ethnic Study of Atherosclerosis (MESA) assessing 881 postmenopausal women, abdominal aortic calcification quantified by computerized tomography was unrelated to estrogen concentrations (40). Recently, in a cross-sectional study on 312 postmenopausal women, a negative correlation of circulating estradiol with PWV was reported, but this association was attenuated in the multivariate model (41). Munir et al. (42) reported similar findings in a cross-sectional study on 126 perimenopausal women; estrogen levels were not independently associated with the presence of coronary and aortic atherosclerosis. On the other hand, there are a few studies showing a favorable role of endogenous sex steroids on the vasculature. In a small case-control study on 33 women with CHD and 17 controls, Li et al. (43) reported a positive correlation of estradiol with FMD, and also in the multivariate model. Wildman et al. (44) showed an inverse relationship of estradiol levels with common carotid artery adventitial layer diameter, even after adjusting for age and other CVD risk factors, whereas no association was found with the other sex steroids. In the study of Jeon et al. (45) on 436 postmenopausal women, higher estradiol levels were independently related to a lower probability of having coronary artery calcification.

Table 2 Summary of studies investigating associations of endogenous estrogen and androgen levels with the severity and mortality of cardio- and cerebro-vascular disease in postmenopausal women (reference in parenthesis).

\begin{tabular}{|c|c|c|c|}
\hline Reference & Study type & $\begin{array}{l}\text { Number of } \\
\text { participants }\end{array}$ & Result \\
\hline (28) & Cross-sectional & 302 & Positive association of $A$ with stroke severity and adverse outcome \\
\hline (27) & Cross-sectional & 60 & Positive association of free testosterone with the degree of CAD \\
\hline (29) & Cross-sectional & 302 & $\begin{array}{l}\text { Independent positive association of E with stroke severity, mortality, } \\
\text { and handicap }\end{array}$ \\
\hline (3) & 19-year FU, population-based & 651 & No association of $E$ and $A$ with CVD mortality \\
\hline (9) & 8-year FU, population-based & 195 & No association of $E$ with mortality \\
\hline (32) & 4.5-year FU, prospective cohort & 2914 & $\begin{array}{l}\text { Negative association of testosterone with all-cause mortality and } \\
\text { CVD event }\end{array}$ \\
\hline (33) & 9-year FU, population-based & 509 & Independent positive association of E with all-cause mortality \\
\hline
\end{tabular}

A, androgen; CAD, coronary artery disease; E, estrogen; FU, follow-up; CVD, cardiovascular disease. 
Concerning the evidence of endogenous androgens, in the study of Creatsa et al. (38), FAI was positively associated with PWV independently of age, smoking, and BMI. These findings agree with those of the large cross-sectional MESA study, where testosterone was independently associated with common carotid IMT after correcting for age, BMI, and insulin resistance. In the same study, there was no significant relationship of endogenous androgens with coronary calcification (39). In a small study on 26 postmenopausal women, FAI was positively related to acetylcholine doses for maximal vasodilation, a surrogate marker of early endothelial dysfunction (46). Few data support an association of endogenous androgens with improved endothelial function. In the study of Montalcini et al. (47) on 60 postmenopausal women, testosterone was independently positively related to FMD in the multivariate regression model. Additionally, an inverse association, independent of CVD risk factors, was demonstrated between $\Delta 4$-androstenedione and free testosterone levels and carotid IMT in a study on 101 women, 48 of which were postmenopausal (48). It should, however, be noted that there are several reports that do not show a significant relationship between endogenous androgens and subclinical atherosclerosis. The study of Calderon-Margalit et al. (49) did not find any link between testosterone and free testosterone and the presence of coronary artery calcification or carotid IMT. Similarly, in the MESA study, endogenous androgens were not related to the presence of aortic calcification (40). Furthermore, in the study of Akishita et al. (50), there was no significant association of sex steroid levels with the brachial FMD. Similar findings were recently reported by Munir et al. (42) concerning the association of androgen levels with the presence of coronary and aortic atherosclerosis.

Current literature, in its majority, suggests a favorable role of endogenous estrogens and an adverse role of androgens on the vasculature. However, there is a substantial body of clinical studies showing no significant association of endogenous sex steroids with early atherosclerotic changes, implying that if a role of endogenous estrogen and androgen levels in the atherosclerotic process is finally confirmed, its magnitude is modest. A summary of these studies is presented in Table 3.

\section{Metabolic parameters}

\section{Coagulation-inflammation}

The menopausal transition is characterized by an increase in inflammatory factors and proatherogenic molecules. With regard to the hemostatic system, Sowers et al. (51) have studied 3302 women and reported that lower estradiol levels were associated with higher levels of plasminogen activator inhibitor-1 and tissue plasminogen activator, whereas there was no significant correlation with fibrinogen, factor VII-c, and high-sensitivity C-reactive protein (CRP). At the same

Table 3 Summary of studies evaluating the association of endogenous estrogen and androgen levels with early markers of atherosclerosis in postmenopausal women (reference in parenthesis).

\begin{tabular}{|c|c|c|c|}
\hline Reference & Study type & $\begin{array}{l}\text { Number of } \\
\text { participants }\end{array}$ & Result \\
\hline \multicolumn{4}{|l|}{ Estrogen } \\
\hline (39) & Cross-sectional & 1947 & No association of E with cIMT and coronary calcification \\
\hline (40) & Cross-sectional & 881 & No association of $\mathrm{E}$ with abdominal aortic calcification \\
\hline (41) & Cross-sectional & 312 & No independent association of E with PWV \\
\hline (42) & Cross-sectional & 126 & $\begin{array}{l}\text { No association of } E \text { with the presence and extent of coronary and aortic } \\
\text { atherosclerosis }\end{array}$ \\
\hline (43) & Case-control & 50 & Positive relationship of $\mathrm{E}$ with FMD \\
\hline (44) & Cross-sectional & 483 & $\begin{array}{l}\text { No association of } E \text { with clMT, but inverse relationship with common } \\
\text { carotid adventitial layer diameter }\end{array}$ \\
\hline (45) & Cross-sectional & 436 & Higher E levels linked to $75 \%$ lower risk of coronary artery calcification \\
\hline (50) & Cross-sectional & 115 & No association of E with FMD \\
\hline \multicolumn{4}{|l|}{ Androgen } \\
\hline (39) & Cross-sectional & 1947 & Positive association of A with cIMT but not with coronary calcification \\
\hline (40) & Cross-sectional & 881 & No association of $A$ with abdominal aortic calcification \\
\hline (42) & Cross-sectional & 126 & $\begin{array}{l}\text { No independent association of } A \text { with the presence and extent of } \\
\text { coronary and aortic atherosclerosis }\end{array}$ \\
\hline (46) & Cross-sectional & 26 & Positive relation of FAI with endothelial dysfunction \\
\hline (47) & Cross-sectional & 101 & Positive correlation of $\mathrm{A}$ with $\mathrm{FMD}$ \\
\hline (48) & Cross-sectional & 101 & Inverse relation of $\mathrm{A}$ with cIMT \\
\hline (49) & 20-year follow-up cohort & 1629 & No association of $\mathrm{A}$ with cIMT and coronary artery calcification \\
\hline (50) & Cross-sectional & 115 & No association of $A$ with FMD \\
\hline
\end{tabular}

E, estrogen; cIMT, carotid intima-medial thickness; PWV, pulse wave velocity; FMD, flow-mediated dilatation; FAl, free androgen index; A, androgen. 
time, Sutton-Tyrrell et al. (52) demonstrated an inverse correlation of estradiol levels with insulin resistance, hemostatic, and inflammatory markers in a population of 3297 pre- and peri-menopausal women. A significant independent positive association between estradiol and CRP concentrations was identified in the population study of Störk et al. (53). Folsom et al. (54) also reported a positive association of estrone levels with CRP concentration in a study on 57 postmenopausal women; however, controlling for obesity attenuated the findings.

With respect to the role of endogenous androgens, in the study of Maturana et al. (55) performed on 53 postmenopausal women, testosterone levels were related to CRP, BMI, as well as endothelin-1 levels, which support associations with a proatherogenic profile. In accordance were the findings of the study of Sutton-Tyrrell et al. (52). In addition, CRP concentration was positively associated with FAI and $\Delta 4$-androstenedione levels in the studies of Störk et al. (53) and Folsom et al. (54) respectively. However, there are also clinical data showing the opposite; in the cross-sectional study of Joffe et al. (56), testosterone was negatively associated with CRP, even after adjusting for the classical CVD risk factors. In the study of Bell et al. including 234 postmenopausal women, testosterone levels were not an independent determinant of CRP and lipid concentrations (57).

It appears that the decrease in estrogen levels accompanying the menopausal transition and the androgenic milieu are linked to a proinflammatory profile promoting atherosclerosis. However, given the heterogeneity of studies and the inconsistency of the described associations, one cannot exclude the possibility that these could be biased by alterations in BMI, insulin sensitivity, and age-related comorbidities accompanying transition to menopause. Given the availability of accurate analytical methods, studies measuring specific inflammation markers, such as proinflammatory cytokines rather than the less specific CRP, and evaluating their relevance with sex hormones seem indicated.

\section{Diabetes mellitus}

There is considerable clinical evidence supporting a positive relationship of endogenous sex steroids with the risk of developing diabetes mellitus (DM). One of the first studies was Khaw \& Barrett-Connor (58) who studied 848 nondiabetic postmenopausal women and found a positive correlation of free testosterone with fasting plasma glucose, independent of age, BMI, and smoking. Circulating estrogen and androgen, i.e. testosterone and $\Delta 4$-androstenedione, were higher in diabetic postmenopausal women compared with the control group in the study of Phillips et al. (59), and this finding was later reproduced by Korytkowski et al. (60). In accordance, the odds of DM were significantly increased with higher testosterone levels in the study of Oh et al. (61), including 233 community-dwelling postmenopausal women. Goodman-Gruen \& Barrett-Connor (62) showed that postmenopausal women with impaired glucose tolerance or DM had significantly higher bioavailable testosterone and estradiol levels compared with the control group. Ding et al. performed a nested case-control study on women health professionals with 359 incident cases of DM, matched 1:1. Both estradiol and testosterone levels were significantly associated with the risk of developing DM, even after adjustment for other metabolic parameters (63), in accordance with the study of Phillips et al. (59). In the large crosssectional study of Golden et al. (64), bioavailable testosterone and estradiol levels were positively associated with the presence of diabetes; however, the relationship of testosterone was attenuated in the multivariate analysis. In the similarly designed study of Kalyani et al., women in the higher quartiles of bioavailable testosterone and estradiol were at an increased risk of DM development. After adjustment for BMI and insulin resistance, however, this relationship remained significant for estradiol but not for testosterone (65).

The follow-up of patients with PCOS provides insight on the long-term effect of androgenicity on glucose metabolism. The incidence of DM was significantly higher in PCOS subjects compared with the control group in a 14-year follow-up (66). Similarly, in a study on 149 PCOS women aged 15-25 years after ovarian wedge resection, an increased occurrence of DM was reported (67). In the study of Margolin et al. (68) on 104 postmenopausal women, the presence of PCOS was significantly related to DM. Furthermore, in the Dutch follow-up study on PCOS women, the prevalence of diabetes in middle-aged women was four times higher compared with the corresponding age group of the general population (69). These findings are in line with previous reports by Wild et al. (20) and Dahlgren et al. (70).

In the field of DM, it seems that available evidence consistently supports a positive relationship of endogenous estrogen and androgen levels with the risk of developing DM.

\section{Lipid profile}

With respect to the link between endogenous sex steroids and lipid profile, data appear inconclusive. In the early studies of Shelley et al. (5) and Berge et al. (71), estradiol and testosterone were not related to lipid concentration. On the contrary, Lambrinoudaki et al. (72) reported an association of higher free estradiol index with an unfavorable lipid profile in healthy postmenopausal women, and this was independent of age, BMI, and insulin resistance. These findings were in the same direction as those of the population-based study of Haffner et al. (73), where estrone levels were inversely related to the HDL/total cholesterol ratio. 
Furthermore, Mudali et al. (74) reported similar results in a case-control study on 328 postmenopausal women. In the MESA study, Vaidya et al. (75) also found that higher estradiol levels were related to a more atherogenic lipoprotein particle profile. On the other hand, in the study of Shakir et al. (76), estradiol correlated inversely with total cholesterol concentration both in women with or without the metabolic syndrome. The authors suggested that the effect, if any, of endogenous sex steroids on CVD markers differs according to the underlying metabolic and cardiovascular status and this is also supported by Sowers et al. In their prospective study on 2863 participants, they showed a modest association of lipoprotein $\alpha$ with estradiol levels in CHD-free women; however, no association was found in women with self-reported CHD (77). Furthermore, Mesalić et al. (78) reported a favorable profile in postmenopausal women with higher estrogen levels, the latter correlating positively with HDL and negatively with VLDL and triglyceride concentrations.

Most studies support positive associations of endogenous androgens with a proatherogenic lipid profile (72, 73). In addition, Svendsen et al. (79) evaluated 121 overweight postmenopausal women and showed an independent negative association of testosterone with HDL concentration. Later, van Beek et al. (80) reported an independent positive association of $\Delta 4$-androstenedione and testosterone with VLDL-triglyceride concentration in postmenopausal women. Free testosterone levels correlated inversely with adiponectin concentration in the study of Milewicz et al. (81), but no association was found with estradiol. Contrary to the previous findings, in their large cross-sectional study, Shakir et al. (76) found that testosterone levels were positively associated with HDL in women without metabolic syndrome.

It is not easy to draw a definite conclusion on the relationship of endogenous sex steroid levels with lipid profile. It is hypothesized that the variable associations reported depend on the underlying cardiometabolic status of the studied population.

\section{Blood pressure}

Even though arterial hypertension is a well-established CVD risk factor, there are a few studies with conflicting results evaluating the clinical relevance of endogenous sex steroid levels with blood pressure (BP). In the longitudinal study of Shelley et al. (5), estradiol was not significantly related to diastolic BP values. In agreement were the more recent studies of Szmuilowicz et al. (82) and Masi et al. (83). Of note, in the study of Szmuilowicz et al., patients had discontinued antihypertensive therapy before hormonal evaluation. However, two studies, one including 253 postmenopausal women and the other with 20 postmenopausal diabetic women and 29 controls, reported a positive association of testosterone levels with BP values $(59,73)$. In the previously mentioned study of Shakir et al., the variable effect of sex steroids according to the presence or absence of metabolic syndrome was shown also for BP. In women with metabolic syndrome, $\Delta 4$-androstenedione was positively associated with systolic BP, and estradiol negatively related to diastolic BP. In women without the syndrome, $\Delta 4$-androstenedione levels again correlated positively with systolic BP, whereas estradiol now appeared to have a positive association with systolic BP (76). Additionally, in the study of Phillips et al. (84), free testosterone levels were an independent determinant of systolic BP values among postmenopausal women, whereas estradiol levels were similar between hypertensive and normotensive women.

Although available data on the role of endogenous sex steroids on BP are limited, the findings of the aforementioned studies suggest a positive link between endogenous androgen and BP. A limiting factor in the accuracy of the results of the previous studies is the use of antihypertensive medication at the time of sex hormone measurement in most, but not in all (82), studies. Larger, adequately powered and homogeneous studies would possibly aid to clarify the clinical relevance of estrogen and androgen levels in BP tuning.

\section{Obesity-insulin resistance-metabolic syndrome}

Insulin resistance and abdominal obesity are the hallmarks of metabolic syndrome tightly associated with CVD. In two recent population-based studies, testosterone was positively related to body fat mass. In the study of Janssen et al. (85) on 359 women, this association was independent of age and CVD risk factors, whereas in the work of Rariy et al.'s (86) model, adjustment for estradiol attenuated this association. Transition to menopause was accompanied by an increase in $\Delta 4$-androstenedione levels and FAI in the study of Mesch et al. (87); FAI was also associated with a higher waist circumference measurement, insulin resistance, and an adverse lipid profile. This agrees with the previous work of Tufano et al. in 44 obese women, half of whom were in the postmenopausal period. FAI was positively related to waist circumference and was significantly higher in menopausal women compared with the premenopausal group (88). In an earlier case-control study of Hauner et al. (89) in women undergoing coronary angiography, testosterone was positively associated with the waist:hip ratio, an index of central adiposity, as well as with insulin levels. A positive association of hyperinsulinemia with total testosterone and FAI was also demonstrated in a study on 104 peri- and postmenopausal women, and this was independent of age, BMI, and time since menopause (90). In the work of Phillips et al. (91), it is suggested that free testosterone might be the underlying mediator 
of both visceral adiposity and insulin resistance in the metabolic syndrome.

Some clinical data suggest a link between androgenicity and the presence of metabolic syndrome. In the study of Golden et al. (92) on 362 postmenopausal women, women in the highest FAI quartiles had fivefold greater odds of meeting the criteria of metabolic syndrome compared with those in the lowest quartiles. In the same line, Maggio et al. (93) showed that Italian women with metabolic syndrome had higher ageadjusted bioavailable testosterone levels in comparison with women without the syndrome. In the 9-year follow-up study with 949 participants investigating the course of menopausal transition, Janssen et al. (94) found that an increase in bioavailable testosterone increased the odds of developing metabolic syndrome. Similarly, in the study of Weinberg et al. (95), postmenopausal women in the highest FAI tertile had a significantly increased risk of the metabolic syndrome, which was observed even after adjustment for BMI and other CVD risk factors. Regarding endogenous estrogen, there are various reports showing a positive relationship with adiposity markers (96). This is not an unexpected finding, as a significant source of estradiol in postmenopausal women is that which is derived from the aromatization of testosterone in the adipose tissue. In the cross-sectional study of Lukanova et al. (97), estrogen and testosterone levels were increased with higher BMI in healthy postmenopausal women and this was recently confirmed in the study of Freeman et al. (98). In agreement, in the study of Olson et al. (99) performed on 207 postmenopausal women undergoing angiography for suspected ischemia, estradiol levels were significantly associated with waist circumference measurement and BMI in the regression analyses. However, in the study of Janssen et al. (94), estradiol levels did not appear to have a significant relationship with the risk of developing metabolic syndrome.

With respect to PCOS-associated hyperandrogenemia and its relevance with the metabolic syndrome, useful information is derived from the follow-up studies of PCOS subjects. In the study of Schmidt et al. (100), postmenopausal women with PCOS showed increased clustering of features of the metabolic syndrome, such as hypertension and hypertriglyceridemia, compared with the control population. Similar results were found in the studies of Margolin et al. (68) and Dahlgren et al. (70) reporting an increased prevalence of central obesity, diabetes, hypertension, and dyslipidemia in PCOS postmenopausal women. Furthermore, in the long-term follow-up study of Hudecova et al. (101), the prevalence of the metabolic syndrome was significantly higher in middle-aged women with a previous diagnosis of PCOS compared with control subjects, independently of the PCOS phenotype or the persistence of PCOS in the reevaluation.

According to the majority of current data, both estrogen and androgen appear to be positively associated with abdominal obesity and the metabolic syndrome. The peripheral aromatization of androgens to estrogens in adipose tissue should be taken into consideration when interpreting the results of various clinical studies. Furthermore, one should note that the metabolic syndrome is the integral of various factors of inflammation, lipid metabolism, and coagulation, all in a complex interplay with sex hormones. Therefore, identifying the independent effect of each sex steroid on CVD and CVD risk factors can often be puzzling.

\section{Conclusion}

In this review, we tried to provide a literature update on the role of endogenous sex steroids on cardio- and cerebro-vascular disease. Clinical studies investigating associations between endogenous estrogen and androgen and vascular alterations in the peri- and postmenopausal period show rather inconsistent results. It is obvious that, although some relationship may be identified, in most studies, the design does not allow its characterization as being causal. Furthermore, the population size is heterogeneous in various studies and a direct comparison of their findings may not be appropriate. Another caveat when trying to draw conclusions is that the mean age of the studied women, which translates in a different time as menopause, varied among the reports that were reviewed. In addition, differences in race and ethnicity should be taken into account in the interpretation of the clinical findings. The majority of the previously mentioned studies concern white population. Of note, in the multi-ethnic MESA study, there was a significant difference in the circulating sex hormone levels between the different races; however, the described associations between sex hormones and markers of atherosclerosis were not modified by ethnic background (39).

It may well be that circulating sex steroid levels represent an index of the general health status. Metabolic features, like adiposity, dyslipidemia, and insulin resistance, often encountered in the postmenopausal age, are a common confounder. As adipose tissue is a significant source of estradiol in postmenopausal women, it is likely that associations with estradiol reflect an association with adrenal and ovarian androgens peripherally aromatized to estrogens.

Well-designed clinical studies and animal models will provide further insight as to whether and how endogenous sex steroids affect the cardio- and cerebrovascular tissue or whether, alternatively, they represent a surrogate marker of the underlying disease. Clarifying the unique role of estrogen and androgen in cardio- and cerebro-vascular disease is an interesting subject of research. Future research will expand our knowledge, and transferring new information from bench to bedside may have significant implications in the clinical setting. 


\section{Declaration of interest}

The authors declare that there is no conflict of interest that could be perceived as prejudicing the impartiality of the research reported.

\section{Funding}

This research did not receive any specific grant from any funding agency in the public, commercial or not-for-profit sector.

\section{References}

1 Manson JE, Hsia J, Johnson KC, Rossouw JE, Assaf AR, Lasser NL, Trevisan M, Black HR, Heckbert SR, Detrano R, Strickland OL, Wong ND, Crouse JR, Stein E \& Cushman M; Women's Health Initiative Investigators. Estrogen plus progestin and the risk of coronary heart disease. New England Journal of Medicine 2003 349 523-534. (doi:10.1056/NEJMoa030808)

2 Wassertheil-Smoller S, Hendrix SL, Limacher M, Heiss G, Kooperberg C, Baird A, Kotchen T, Curb JD, Black H, Rossouw JE, Aragaki A, Safford M, Stein E, Laowattana S \& Mysiw WJ; WHI Investigators. Effect of estrogen plus progestin on stroke in postmenopausal women: the Women's Health Initiative: a randomized trial. Journal of the American Medical Association 2003289 2673-2684. (doi:10.1001/jama.289.20. 2673)

3 Barrett-Connor E \& Goodman-Gruen D. Prospective study of endogenous sex hormones and fatal cardiovascular disease in postmenopausal women. BMJ $1995 \mathbf{3 1 1}$ 1193-1196. (doi:10.1136/bmj.311.7014.1193)

4 Price JF, Lee AJ \& Fowkes FG. Steroid sex hormones and peripheral arterial disease in the Edinburgh Artery Study. Steroids 199762 789-794. (doi:10.1016/S0039-128X(97)00103-7)

5 Shelley JM, Green A, Smith AM, Dudley E, Dennerstein L, Hopper J \& Burger H. Relationship of endogenous sex hormones to lipids and blood pressure in mid-aged women. Annals of Epidemiology 19988 39-45. (doi:10.1016/S1047-2797(97) 00123-3)

6 Roquer J, Campello AR \& Gomis M. Sex differences in first-ever acute stroke. Stroke 200334 1581-1585. (doi:10.1161/01.STR. 0000078562.82918.F6)

7 Rosamond W, Flegal K, Furie K, Go A, Greenlund K, Haase N, Hailpern SM, Ho M, Howard V, Kissela B, Kittner S, Lloyd-Jones D, McDermott M, Meigs J, Moy C, Nichol G, O'Donnell C, Roger V, Sorlie P, Steinberger J, Thom T, Wilson M \& Hong Y; American Heart Association Statistics Committee and Stroke Statistics Subcommittee. Heart disease and stroke statistics-2008 update: a report from the American Heart Association Statistics Committee and Stroke Statistics Subcommittee. Circulation 2008 117 e25-e146. (doi:10.1161/CIRCULATIONAHA.107.187998)

8 Cauley JA, Gutai JP, Glynn NW, Paternostro-Bayles M, Cottington E \& Kuller LH. Serum estrone concentrations and coronary artery disease in postmenopausal women. Arteriosclerosis and Thrombosis $1994 \mathbf{1 4} 14-18$. (doi:10.1161/01.ATV. 14.1.14)

9 Nilsson SE, Fransson E \& Brismar K. Relationship between serum progesterone concentrations and cardiovascular disease, diabetes, and mortality in elderly Swedish men and women: an 8-year prospective study. Gender Medicine 20096 433-443. (doi:10.1016/j.genm.2009.09.011)

10 Lee JS, Yaffe K, Lui LY, Cauley J, Taylor B, Browner W \& Cummings S; Study of Osteoporotic Fractures Group. Prospective study of endogenous circulating estradiol and risk of stroke in older women. Archives of Neurology 201067 195-201. (doi:10. 1001/archneurol.2009.322)

11 Chen Y, Zeleniuch-Jacquotte A, Arslan AA, Wojcik O, Toniolo P, Shore RE, Levitz M \& Koenig KL. Endogenous hormones and coronary heart disease in postmenopausal women. Atherosclerosis 2011216 414-419. (doi:10.1016/j.atherosclerosis.2011.01. 053)

12 Rexrode KM, Manson JE, Lee IM, Ridker PM, Sluss PM, Cook NR \& Buring JE. Sex hormone levels and risk of cardiovascular events in postmenopausal women. Circulation 2003108 1688-1693. (doi:10.1161/01.CIR.0000091114.36254.F3)

13 Patel SM, Ratcliffe SJ, Reilly MP, Weinstein R, Bhasin S, Blackman MR, Cauley JA, Sutton-Tyrrell K, Robbins J, Fried LP \& Cappola AR. Higher serum testosterone concentration in older women is associated with insulin resistance, metabolic syndrome, and cardiovascular disease. Journal of Clinical Endocrinology and Metabolism 200994 4776-4784. (doi:10. 1210/jc.2009-0740)

14 Page-Wilson G, Goulart AC \& Rexrode KM. Interrelation between sex hormones and plasma sex hormone-binding globulin and hemoglobin A1c in healthy postmenopausal women. Metabolic Syndrome and Related Disorders 20097 249-254. (doi:10.1089/ met.2008.0081)

15 Christakou CD \& Diamanti-Kandarakis E. Role of androgen excess on metabolic aberrations and cardiovascular risk in women with polycystic ovary syndrome. Women's Health 20084 583-594. (doi:10.2217/17455057.4.6.583)

16 Markopoulos MC, Rizos D, Valsamakis G, Deligeoroglou E, Grigoriou O, Chrousos GP, Creatsas G \& Mastorakos G. Hyperandrogenism in women with polycystic ovary syndrome persists after menopause. Journal of Clinical Endocrinology and Metabolism 201196 623-631. (doi:10.1210/jc.2010-0130)

17 Puurunen J, Piltonen T, Morin-Papunen L, Perheentupa A, Järvelä I, Ruokonen A \& Tapanainen JS. Unfavorable hormonal, metabolic, and inflammatory alterations persist after menopause in women with PCOS. Journal of Clinical Endocrinology and Metabolism 201196 1827-1834. (doi:10.1210/jc.2011-0039)

18 de Groot PC, Dekkers OM, Romijn JA, Dieben SW \& Helmerhorst FM. PCOS, coronary heart disease, stroke and the influence of obesity: a systematic review and meta-analysis. Human Reproduction Update 201117 495-500. (doi:10.1093/ humupd/dmrO01)

19 Shaw LJ, Bairey Merz CN, Azziz R, Stanczyk FZ, Sopko G, Braunstein GD, Kelsey SF, Kip KE, Cooper-Dehoff RM, Johnson BD, Vaccarino V, Reis SE, Bittner V, Hodgson TK, Rogers W \& Pepine CJ. Postmenopausal women with a history of irregular menses and elevated androgen measurements at high risk for worsening cardiovascular event-free survival: results from the National Institutes of Health - National Heart, Lung, and Blood Institute sponsored Women's Ischemia Syndrome Evaluation. Journal of Clinical Endocrinology and Metabolism 2008 93 1276-1284. (doi:10.1210/jc.2007-0425)

20 Wild S, Pierpoint T, McKeigue P \& Jacobs H. Cardiovascular disease in women with polycystic ovary syndrome at long-term follow-up: a retrospective cohort study. Clinical Endocrinology 200052 595-600. (doi:10.1046/j.1365-2265.2000.01000.x)

21 Debing E, Peeters E, Duquet W, Poppe K, Velkeniers B \& Van den Brande P. Endogenous sex hormone levels in postmenopausal women undergoing carotid artery endarterectomy. European Journal of Endocrinology 2007156 687-693. (doi:10.1530/ EJE-06-0702)

22 Montalcini T, Gorgone G, Gazzaruso C, Sesti G, Perticone F \& Pujia A. Role of endogenous androgens on carotid atherosclerosis in non-obese postmenopausal women. Nutrition, Metabolism, and Cardiovascular Diseases $2007 \mathbf{1 7}$ 705-711. (doi:10.1016/j. numecd.2006.09.007)

23 Golden SH, Maguire A, Ding J, Crouse JR, Cauley JA, Zacur H \& Szklo M. Endogenous postmenopausal hormones and carotid atherosclerosis: a case-control study of the atherosclerosis risk in communities cohort. American Journal of Epidemiology 2002155 437-445. (doi:10.1093/aje/155.5.437)

24 Naessen T, Sjogren U, Bergquist J, Larsson M, Lind L \& Kushnir MM. Endogenous steroids measured by high-specificity liquid chromatography-tandem mass spectrometry and 
prevalent cardiovascular disease in 70-year-old men and women. Journal of Clinical Endocrinology and Metabolism 2010951889 1897. (doi:10.1210/jc.2009-1722)

25 Laughlin GA, Goodell V \& Barrett-Connor E. Extremes of endogenous testosterone are associated with increased risk of incident coronary events in older women. Journal of Clinical Endocrinology and Metabolism 201095 740-747. (doi:10.1210/ jc.2009-1693)

26 Braunstein GD, Johnson BD, Stanczyk FZ, Bittner V, Berga SL, Shaw L, Hodgson TK, Paul-Labrador M, Azziz R \& Merz CN. Relations between endogenous androgens and estrogens in postmenopausal women with suspected ischemic heart disease. Journal of Clinical Endocrinology and Metabolism 200893 4268-4275. (doi:10.1210/jc.2008-0792)

27 Phillips GB, Pinkernell BH \& Jing TY. Relationship between serum sex hormones and coronary artery disease in postmenopausal women. Arteriosclerosis, Thrombosis, and Vascular Biology 1997 17 695-701. (doi:10.1161/01.ATV.17.4.695)

28 Pappa T, Vemmos K, Saltiki K, Mantzou E, Stamatelopoulos K \& Alevizaki M. Severity and outcome of acute stroke in women: relation to adrenal sex steroid levels. Metabolism 201261 84-91. (doi:10.1016/j.metabol.2011.06.003)

29 Pappa T, Vemmos K, Mantzou E, Savvari P, Stamatelopoulos K \& Alevizaki M. Estradiol levels predict short-term adverse health outcomes in postmenopausal acute stroke women. European Journal of Neurology 2012 In press. (doi:10.1111/j.1468-1331. 2012.03714.x)

30 Saltiki K, Cimponeriu A, Garofalaki M, Sarika L, Papathoma A, Stamatelopoulos K \& Alevizaki M. Severity of coronary artery disease in postmenopausal women: association with the androgen receptor gene (CAG) $n$ repeat polymorphism. Menopause 201118 1225-1231. (doi:10.1097/gme.0b013e31821b81b8)

31 Alevizaki M, Saltiki K, Cimponeriu A, Kanakakis I, Xita N, Alevizaki CC, Georgiou I \& Sarika HL. Severity of cardiovascular disease in postmenopausal women: associations with common estrogen receptor $\alpha$ polymorphic variants. European Journal of Endocrinology 2007156 489-496. (doi:10.1530/EJE-06-0685)

32 Sievers C, Klotsche J, Pieper L, Schneider HJ, März W, Wittchen HU, Stalla GK \& Mantzoros C. Low testosterone levels predict all-cause mortality and cardiovascular events in women: a prospective cohort study in German primary care patients. European Journal of Endocrinology 2010163 699-708. (doi:10. 1530/EJE-10-0307)

33 Maggio M, Ceda GP, Lauretani F, Bandinelli S, Ruggiero C, Guralnik JM, Metter EJ, Ling SM, Paolisso G, Valenti G, Cappola AR \& Ferrucci L. Relationship between higher estradiol levels and 9-year mortality in older women: the Invecchiare in Chianti study. Journal of the American Geriatrics Society 200957 1810-1815. (doi:10.1111/j.1532-5415.2009.02464.x)

34 Alevizaki M, Saltiki K, Xita N, Cimponeriu A, Stamatelopoulos K, Mantzou E, Doukas C \& Georgiou I. The importance of the (TAAAA) $n$ alleles at the SHBG gene promoter for the severity of coronary artery disease in postmenopausal women. Menopause 200815 461-468. (doi:10.1097/gme.0b013e31814faf41)

35 Saltiki K, Stamatelopoulos K, Voidonikola P, Lazaros L, Mantzou E, Georgiou I, Anastasiou E, Papamichael C \& Alevizaki M. Association of the SHBG gene promoter polymorphism with early markers of atherosclerosis in apparently healthy women. Atherosclerosis 2011219 205-210. (doi:10. 1016/j.atherosclerosis.2011.06.053)

$36 \mathrm{Wu}$ FC \& von Eckardstein A. Androgens and coronary artery disease. Endocrine Reviews 200324 183-217. (doi:10.1210/er. 2001-0025)

37 Brand JS \& van der Schouw YT. Testosterone SHBG and cardiovascular health in postmenopausal women. International Journal of Impotence Research 201022 91-104. (doi:10.1038/ijir. 2009.64)

38 Creatsa M, Armeni E, Stamatelopoulos K, Rizos D, Georgiopoulos G, Kazani M, Alexandrou A, Dendrinos S, Augoulea A, Papamichael C \& Lambrinoudaki I. Circulating androgen levels are associated with subclinical atherosclerosis and arterial stiffness in healthy recently menopausal women. Metabolism 201261 193-201. (doi:10.1016/j.metabol.2011. 06.005)

39 Ouyang P, Vaidya D, Dobs A, Golden SH, Szklo M, Heckbert SR, Kopp P \& Gapstur SM. Sex hormone levels and subclinical atherosclerosis in postmenopausal women: the Multi-Ethnic Study of Atherosclerosis. Atherosclerosis 2009204 255-261. (doi:10.1016/j.atherosclerosis.2008.08.037)

40 Michos ED, Vaidya D, Gapstur SM, Schreiner PJ, Golden SH, Wong ND, Criqui MH \& Ouyang P. Sex hormones, sex hormone binding globulin, and abdominal aortic calcification in women and men in the multi-ethnic study of atherosclerosis (MESA). Atherosclerosis 2008200 432-438. (doi:10.1016/j.atherosclerosis.2007.12.032)

41 Giallauria F, Ling SM, Schreiber C, Maggio M, Shetty V, Muller D, Vigorito C, Ferrucci L \& Najjar SS. Arterial stiffness and bone demineralization: the Baltimore longitudinal study of aging. American Journal of Hypertension 201124 970-975. (doi:10. 1038/ajh.2011.80)

42 Munir JA, Wu H, Bauer K, Bindeman J, Byrd C, Feuerstein IM, Villines TC \& Taylor AJ. The perimenopausal atherosclerosis transition: relationships between calcified and noncalcified coronary, aortic, and carotid atherosclerosis and risk factors and hormone levels. Menopause 201219 10-15. (doi:10.1097/ gme.0b013e318221bc8d)

43 Li XP, Zhou Y, Zhao SP, Gao M, Zhou QC \& Li YS. Effect of endogenous estrogen on endothelial function in women with coronary heart disease and its mechanism. Clinica Chimica Acta 2004339 183-188. (doi:10.1016/j.cccn.2003.10.006)

44 Wildman RP, Colvin AB, Powell LH, Matthews KA, EversonRose SA, Hollenberg S, Johnston JM \& Sutton-Tyrrell K. Associations of endogenous sex hormones with the vasculature in menopausal women: the Study of Women's Health Across the Nation (SWAN). Menopause 200815 414-421. (doi:10.1097/ gme.0b013e318154b6f5)

45 Jeon GH, Kim SH, Yun SC, Chae HD, Kim CH \& Kang BM. Association between serum estradiol level and coronary artery calcification in postmenopausal women. Menopause 201017 902-907. (doi:10.1097/gme.0b013e3181d76768)

46 Maturana MA, Rubira MC, Consolim-Colombo F, Irigoyen MC \& Spritzer PM. Androgenicity and venous endothelial function in post-menopausal women. Journal of Endocrinological Investigation 201033 239-243. (doi:10.3275.6559)

47 Montalcini T, Gorgone G, Gazzaruso C, Sesti G, Perticone F \& Pujia A. Endogenous testosterone and endothelial function in postmenopausal women. Coronary Artery Disease 2007 18 9-13. (doi:10.1097/01.mca.0000236290.79306.d1)

48 Bernini GP, Sgro' M, Moretti A, Argenio GF, Barlascini CO, Cristofani R \& Salvetti A. Endogenous androgens and carotid intimal-medial thickness in women. Journal of Clinical Endocrinology and Metabolism 199984 2008-2012. (doi:10.1210/jc. 84.6.2008)

49 Calderon-Margalit R, Schwartz SM, Wellons MF, Lewis CE, Daviglus ML, Schreiner PJ, Williams OD, Sternfeld B, Carr JJ, O'Leary DH, Sidney S, Friedlander Y \& Siscovick DS. Prospective association of serum androgens and sex hormone-binding globulin with subclinical cardiovascular disease in young adult women: the "Coronary Artery Risk Development in Young Adults" women's study. Journal of Clinical Endocrinology and Metabolism 201095 4424-4431. (doi:10.1210/jc.2009-2643)

50 Akishita M, Hashimoto M, Ohike Y, Ogawa S, Iijima K, Eto M \& Ouchi Y. Association of plasma dehydroepiandrosterone-sulfate levels with endothelial function in postmenopausal women with coronary risk factors. Hypertension Research 200831 69-74. (doi:10.1291/hypres.31.69)

51 Sowers MR, Matthews KA, Jannausch M, Randolph JF, McConnell D, Sutton-Tyrrell K, Little R, Lasley B \& Pasternak R. Hemostatic factors and estrogen during the menopausal transition. Journal of Clinical Endocrinology and Metabolism 200590 5942-5948. (doi:10.1210/jc.2005-0591) 
52 Sutton-Tyrrell K, Wildman RP, Matthews KA, Chae C, Lasley BL, Brockwell S, Pasternak RC, Lloyd-Jones D, Sowers MF \& Torréns JI; SWAN Investigators. Sex-hormone-binding globulin and the free androgen index are related to cardiovascular risk factors in multiethnic premenopausal and perimenopausal women enrolled in the Study of Women Across the Nation (SWAN). Circulation 2005111 1242-1249. (doi:10.1161/01. CIR.0000157697.54255.CE)

53 Störk S, Bots ML, Grobbee DE \& van der Schouw YT. Endogenous sex hormones and C-reactive protein in healthy postmenopausal women. Journal of Internal Medicine 2008264 245-253. (doi:10. 1111/j.1365-2796.2008.01946.x)

54 Folsom AR, Golden SH, Boland LL \& Szklo M. Association of endogenous hormones with C-reactive protein, fibrinogen, and white blood count in post-menopausal women. European Journal of Epidemiology 200520 1015-1022. (doi:10.1007/ s10654-005-3657-0)

55 Maturana MA, Breda V, Lhullier F \& Spritzer PM. Relationship between endogenous testosterone and cardiovascular risk in early postmenopausal women. Metabolism 200857 961-965. (doi:10.1016/j.metabol.2008.02.012)

56 Joffe HV, Ridker PM, Manson JE, Cook NR, Buring JE \& Rexrode KM. Sex hormone-binding globulin and serum testosterone are inversely associated with C-reactive protein levels in postmenopausal women at high risk for cardiovascular disease. Annals of Epidemiology 200616 105-112. (doi:10.1016/j. annepidem.2005.07.055)

57 Bell RJ, Davison SL, Papalia MA, McKenzie DP \& Davis SR. Endogenous androgen levels and cardiovascular risk profile in women across the adult life span. Menopause 200714 630-638.

58 Khaw KT \& Barrett-Connor E. Fasting plasma glucose levels and endogenous androgens in non-diabetic postmenopausal women. Clinical Science 199180 199-203.

59 Phillips GB, Tuck CH, Jing TY, Boden-Albala B, Lin IF, Dahodwala N \& Sacco RL. Association of hyperandrogenemia and hyperestrogenemia with type 2 diabetes in Hispanic postmenopausal women. Diabetes Care 200023 74-79. (doi:10.2337/diacare.23.1.74)

60 Korytkowski MT, Krug EI, Daly MA, Deriso L, Wilson JW \& Winters SJ. Does androgen excess contribute to the cardiovascular risk profile in postmenopausal women with type 2 diabetes? Metabolism $2005 \mathbf{5 4}$ 1626-1631. (doi:10.1016/j.metabol. 2005.06.011)

61 Oh JY, Barrett-Connor E, Wedick NM \& Wingard DL; Rancho Bernardo Study. Endogenous sex hormones and the development of type 2 diabetes in older men and women: the Rancho Bernardo study. Diabetes Care 200225 55-60. (doi:10.2337/diacare.25.1. 55)

62 Goodman-Gruen D \& Barrett-Connor E. Sex differences in the association of endogenous sex hormone levels and glucose tolerance status in older men and women. Diabetes Care 2000 23 912-918. (doi:10.2337/diacare.23.7.912)

63 Ding EL, Song Y, Manson JE, Rifai N, Buring JE \& Liu S. Plasma sex steroid hormones and risk of developing type 2 diabetes in women: a prospective study. Diabetologia 200750 2076-2084. (doi:10.1007/s00125-007-0785-y)

64 Golden SH, Dobs AS, Vaidya D, Szklo M, Gapstur S, Kopp P, Liu K \& Ouyang P. Endogenous sex hormones and glucose tolerance status in postmenopausal women. Journal of Clinical Endocrinology and Metabolism 200792 1289-1295. (doi:10.1210/ jc. 2006-1895)

65 Kalyani RR, Franco M, Dobs AS, Ouyang P, Vaidya D, Bertoni A, Gapstur SM \& Golden SH. The association of endogenous sex hormones, adiposity, and insulin resistance with incident diabetes in postmenopausal women. Journal of Clinical Endocrinology and Metabolism 200994 4127-4135. (doi:10.1210/jc. 2009-0910)

66 Hudecova M, Holte J, Olovsson M, Larsson A, Berne C \& Poromaa IS. Diabetes and impaired glucose tolerance in patients with polycystic ovary syndrome - a long term follow-up. Human Reproduction 201126 1462-1468. (doi:10.1093/humrep/ der065)

67 Lunde O \& Tanbo T. Polycystic ovary syndrome: a follow-up study on diabetes mellitus, cardiovascular disease and malignancy 15-25 years after ovarian wedge resection. Gynecological Endocrinology 200723 704-709. (doi:10.1080/0951359070 1705189)

68 Margolin E, Zhornitzki T, Kopernik G, Kogan S, Schattner A \& Knobler H. Polycystic ovary syndrome in post-menopausal women - marker of the metabolic syndrome. Maturitas 2005 50 331-336. (doi:10.1016/j.maturitas.2004.09.005)

69 Elting MW, Korsen TJ, Bezemer PD \& Schoemaker J. Prevalence of diabetes mellitus, hypertension and cardiac complaints in a follow-up study of a Dutch PCOS population. Human Reproduction 200116 556-560. (doi:10.1093/humrep/16.3.556)

70 Dahlgren E, Johansson S, Lindstedt G, Knutsson F, Odén A, Janson PO, Mattson LA, Crona N \& Lundberg PA. Women with polycystic ovary syndrome wedge resected in 1956 to 1965 : a long-term follow-up focusing on natural history and circulating hormones. Fertility and Sterility 199257 505-513. (doi:10.1016/0020-7292(92)90704-M)

71 Berge LN, Bønaa KH \& Nordøy A. Serum ferritin, sex hormones, and cardiovascular risk factors in healthy women. Arteriosclerosis and Thrombosis 199414 857-861. (doi:10.1161/01.ATV.14.6. 857)

72 Lambrinoudaki I, Christodoulakos G, Rizos D, Economou E, Argeitis J, Vlachou S, Creatsa M, Kouskouni E \& Botsis D. Endogenous sex hormones and risk factors for atherosclerosis in healthy Greek postmenopausal women. European Journal of Endocrinology 2006154 907-916. (doi:10.1530/eje.1.02167)

73 Haffner SM, Newcomb PA, Marcus PM, Klein BE \& Klein R. Relation of sex hormones and dehydroepiandrosterone sulfate (DHEA-SO $\mathrm{S}_{4}$ ) to cardiovascular risk factors in postmenopausal women. American Journal of Epidemiology $1995142925-934$.

74 Mudali S, Dobs AS, Ding J, Cauley JA, Szklo M \& Golden SH; atherosclerosis risk in communities study. Endogenous postmenopausal hormones and serum lipids: the atherosclerosis risk in communities study. Journal of Clinical Endocrinology and Metabolism 200590 1202-1209. (doi:10.1210/jc.2004-0744)

75 Vaidya D, Dobs A, Gapstur SM, Golden SH, Hankinson A, Liu K \& Ouyang P. The association of endogenous sex hormones with lipoprotein subfraction profile in the Multi-Ethnic Study of Atherosclerosis. Metabolism 200857 782-790. (doi:10.1016/ j.metabol.2008.01.019)

76 Shakir YA, Samsioe G, Nyberg P, Lidfeldt J, Nerbrand C \& Agardh CD. Do sex hormones influence features of the metabolic syndrome in middle-aged women? A population-based study of Swedish women: the Women's Health in the Lund Area (WHILA) Study. Fertility and Sterility 200788 163-171. (doi:10.1016/j. fertnstert.2006.11.111)

77 Sowers M, Crawford SL, Cauley JA \& Stein E. Association of lipoprotein(a), insulin resistance, and reproductive hormones in a multiethnic cohort of pre- and perimenopausal women (The SWAN Study). American Journal of Cardiology 200392 533-537. (doi:10.1016/S0002-9149(03)00720-3)

78 Mesalić L, Tupković E, Kendić S \& Balić D. Correlation between hormonal and lipid status in women in menopause. Bosnian Journal of Basic Medical Sciences 2008 8 188-192.

79 Svendsen OL, Hassager C \& Christiansen C. Relationships and independence of body composition, sex hormones, fat distribution and other cardiovascular risk factors in overweight postmenopausal women. International Journal of Obesity and Related Metabolic Disorders 199317 459-463.

80 Van Beek AP, de Ruijter-Heijstek FC, Jansen H, Erkelens DW \& de Bruin TW. Sex steroids and plasma lipoprotein levels in healthy women: the importance of androgens in the estrogen-deficient state. Metabolism 200453 187-192. (doi:10.1016/j.metabol. 2003.07.022) 
81 Milewicz A, Zatonska K, Demissie M, Jêdrzejuk D, Dunajska K, Ilow R \& Lwow F. Serum adiponectin concentration and cardiovascular risk factors in climacteric women. Gynecological Endocrinology 200520 68-73. (doi:10.1080/09513590400020989)

82 Szmuilowicz ED, Adler GK, Ricchiuti V, Hopkins PN \& Seely EW. Relationships between endogenous sex hormone concentrations and vascular function in postmenopausal women. Journal of Clinical Endocrinology and Metabolism 200792 4738-4741. (doi:10.1210/jc.2007-1471)

83 Masi CM, Hawkley LC, Xu X, Veenstra TD \& Cacioppo JT. Serum estrogen metabolites and systolic blood pressure among middleaged and older women and men. American Journal of Hypertension 200922 1148-1153. (doi:10.1038/ajh.2009.155)

84 Phillips GB, Jing TY \& Laragh JH. Serum sex hormone levels in postmenopausal women with hypertension. Journal of Human Hypertension 199711 523-526. (doi:10.1038/sj.jhh.1000481)

85 Janssen I, Powell LH, Kazlauskaite R \& Dugan SA. Testosterone and visceral fat in midlife women: the Study of Women's Health Across the Nation (SWAN) fat patterning study. Obesity 201018 604-610. (doi:10.1038/oby.2009.251)

86 Rariy CM, Ratcliffe SJ, Weinstein R, Bhasin S, Blackman MR, Cauley JA, Robbins J, Zmuda JM, Harris TB \& Cappola AR. Higher serum free testosterone concentration in older women is associated with greater bone mineral density, lean body mass, and total fat mass: the cardiovascular health study. Journal of Clinical Endocrinology and Metabolism 201196 989-996. (doi:10.1210/jc.2010-0926)

87 Mesch VR, Siseles NO, Maidana PN, Boero LE, Sayegh F, Prada M, Royer M, Schreier L, Benencia HJ \& Berg GA. Androgens in relationship to cardiovascular risk factors in the menopausal transition. Climacteric 200811 509-517. (doi:10.1080/ $13697130802416640)$

88 Tufano A, Marzo P, Enrini R, Morricone L, Caviezel F \& Ambrosi B. Anthropometric, hormonal and biochemical differences in lean and obese women before and after menopause. Journal of Endocrinological Investigation 200427 648-653.

89 Hauner H, Bognar E \& Blum A. Body fat distribution and its association with metabolic and hormonal risk factors in women with angiographically assessed coronary artery disease. Evidence for the presence of a metabolic syndrome. Atherosclerosis 1994 105 209-216. (doi:10.1016/0021-9150(94)90051-5)

90 Maturana MA \& Spritzer PM. Association between hyperinsulinemia and endogenous androgen levels in peri- and postmenopausal women. Metabolism 200251 238-243. (doi:10.1053/ meta.2002.29997)

91 Phillips GB, Jing T \& Heymsfield SB. Does insulin resistance, visceral adiposity, or a sex hormone alteration underlie the metabolic syndrome? Studies in women. Metabolism $2008 \mathbf{5 7}$ 838-844. (doi:10.1016/j.metabol.2008.01.029)

92 Golden SH, Ding J, Szklo M, Schmidt MI, Duncan BB \& Dobs A. Glucose and insulin components of the metabolic syndrome are associated with hyperandrogenism in postmenopausal women: the atherosclerosis risk in communities study. American Journal of Epidemiology 2004160 540-548. (doi:10.1093/aje/kwh250)

93 Maggio M, Lauretani F, Ceda GP, Bandinelli S, Basaria S, Paolisso G, Ble A, Egan JM, Metter EJ, Abbatecola AM,
Zuliani G, Ruggiero C, Valenti G, Guralnik JM \& Ferrucci L. Association of hormonal dysregulation with metabolic syndrome in older women: data from the InCHIANTI study. American Journal of Physiology. Endocrinology and Metabolism 2007292 E353-E358. (doi:10.1152/ajpendo.00339.2006)

94 Janssen I, Powell LH, Crawford S, Lasley B \& Sutton-Tyrrell K. Menopause and the metabolic syndrome: the Study of Women's Health Across the Nation. Archives of Internal Medicine $2008 \mathbf{1 6 8}$ 1568-1575. (doi:10.1001/archinte.168.14.1568)

95 Weinberg ME, Manson JE, Buring JE, Cook NR, Seely EW, Ridker PM \& Rexrode KM. Low sex hormone-binding globulin is associated with the metabolic syndrome in postmenopausal women. Metabolism 200655 1473-1480. (doi:10.1016/j. metabol.2006.06.017)

96 McTiernan A, Wu L, Chen C, Chlebowski R, MossavarRahmani Y, Modugno F, Perri MG, Stanczyk FZ, Van Horn L \& Wang CY; Women's Health Initiative Investigators. Relation of BMI and physical activity to sex hormones in postmenopausal women. Obesity 200614 1662-1677. (doi:10.1038/oby. 2006.191)

97 Lukanova A, Lundin E, Zeleniuch-Jacquotte A, Muti P, Mure A, Rinaldi S, Dossus L, Micheli A, Arslan A, Lenner P, Shore RE, Krogh V, Koenig KL, Riboli E, Berrino F, Hallmans G, Stattin P, Toniolo P \& Kaaks R. Body mass index, circulating levels of sex-steroid hormones, IGF-I and IGF-binding protein-3: a cross-sectional study in healthy women. European Journal of Endocrinology 2004150 161-171. (doi:10.1530/eje. $0.1500161)$

98 Freeman EW, Sammel MD, Lin H \& Gracia CR. Obesity and reproductive hormone levels in the transition to menopause. Menopause 201017 718-726. (doi:10.1097/gme.0b013e3181 db9f8b)

99 Olson MB, Shaw LJ, Kaizar EE, Kelsey SF, Bittner V, Reis SE, Smith K, Braunstein GD, Berga SL, Johnson BD \& Bairey Merz CN; WISE Study Group. Obesity distribution and reproductive hormone levels in women: a report from the NHLBI-sponsored WISE Study. Journal of Women's Health 200615 836-842. (doi:10.1089/jwh.2006.15.836)

100 Schmidt J, Landin-Wilhelmsen K, Brännström M \& Dahlgren E. Cardiovascular disease and risk factors in PCOS women of postmenopausal age: a 21-year controlled follow-up study. Journal of Clinical Endocrinology and Metabolism 201196 3794-3803. (doi:10.1210/jc.2011-1677)

101 Hudecova M, Holte J, Olovsson M, Larsson A, Berne C \& Sundstrom-Poromaa I. Prevalence of the metabolic syndrome in women with a previous diagnosis of polycystic ovary syndrome: long-term follow-up. Fertility and Sterility 201196 1271-1274. (doi:10.1016/j.fertnstert.2011.08.006)

Received 9 March 2012

Revised version received 29 April 2012

Accepted 18 May 2012 